\title{
AN INVESTIGATION INTO THE USE OF STRAIN ROSETTES FOR THE MEASUREMENT OF PROPAGATING GYGLIC STRAINS
}

\author{
By Vernon A. SQuire \\ (Scott Polar Research Institute, Cambridge CB2 IER, England)
}

\begin{abstract}
An investigation into the feasibility of using a strain rosette to measure the principal strains and to locate the principal axes for a propagating strain wave is carried out for the particular application of a flexural-gravity wave in sea ice. It is found that the separation of the instruments in the rosette is extremely critical and, for a physically realizable rosette, errors are unavoidable if strain is to be monitored continuously. An alternative approach is proposed employing frequency-domain analysis and in particular a running-power spectral density. The method is demonstrated with data obtained from strainmeters on fast ice in Notre Dame Bay, Newfoundland. Two distinct wave components are found to be present of period $6 \mathrm{~s}$ and $13 \mathrm{~s}$, and it is shown with $99.9 \%$ confidence that they are propagating in different directions.
\end{abstract}

RÉsumé. Une recherche sur l'utilisation de rosettes de déformation pour la mesure de la propagation de déformations cycliques. On a conduit une recherche sur la faisabilité de l'utilisation d'une rosette de déformation pour mesurer les principales déformations et pour situer les directions principales d'un tracé d'ondes en mouvement, dans le cas particulier d'une onde de flexion-gravité dans une glace de mer. On trouve que la séparation des instruments dans la rosette est extrêmement délicate et que, pour une rosette physiquement réalisable, les erreurs sont inévitables s'il est nécessaire d'afficher la déformation en continu. On propose une solution de rechange en employant l'analyse du domaine de fréquences et en particulier de la densité spectrale. On a essayé la méthode avec des données obtenues par des capteurs de déformation sur la glace fixée dans Notre Dame Bay, Newfoundland. Deux ondes composantes distinctes ont été trouvées de périodes $6 \mathrm{~s}$ et $13 \mathrm{~s}$ et l'on montre avec une confiance de $99,9 \%$ qu'elles se propagent dans des directions différentes.

Zusammenfassung. Eine Untersuchung zur Anwendung von Spannungsrosetten für die Messung von fortschreitenden zyklischen Spannungen. Für die spezielle Anwendung auf eine schwerkraftinduzierte Biegungswelle in Meereis wurde eine Untersuchung über die Zweckmässigkeit des Gebrauchs von Spannungsrosetten zur Messung der Hauptspannungen und zur Lokalisierung der Hauptachsen einer fortschreitenden Spannungswelle angestellt. Es ergibt sich, dass der räumliche Abstand der Messinstrumente in der Rosette ausserordentliche Bedeutung besitzt und dass in physikalisch realisierbaren Rosetten unvermeidliche Messfehler auftreten, wenn die Spannung kontinuierlich aufgezeichnet werden soll. Es wird deshalb ein anderes Verfahren vorgeschlagen, das die Frequenzbereichsanalyse und besonders die fortlaufende spektrale Wirkungsdichte heranzieht. Diese Methode wird anhand von Daten vorgeführt, die von Dehnungsmessern auf dem Festeis in der NotreDame-Bay von Neufundland stammen. Es lassen sich zwei verschiedene Wellenkomponenten mit Perioden von $6 \mathrm{~s}$ und ${ }_{1} 3 \mathrm{~s}$ feststellen und es wird mit einer Zuverlässigkeit von 99,9\% gezeigt, dass sie sich in verschiedenen Richtungen fortpflanzen.

\section{INTRODUCTION}

It has long been recognized by engineers that the physical length of a strain-measuring instrument is extremely important when computing transients or cyclic strains (Dove and Adams, I964, p. I95-24I ; Dally and Riley, 1965, p. 399-421; Murphy and others, 1957). In the case of a propagating dynamic strain pulse, the ratio of the strain-gauge length to the pulse length is critical, and totally fictitious results may be obtained if this is not taken into account. A gauge employed to measure the strain at a point on a standing sinusoidal oscillation will in fact measure the average strain over the gauge length. The error will depend on the ratio of the gauge length to the wavelength of the sinusoid.

This paper demonstrates another source of error which results from the measurement of a propagating strain wave by a rosette of three gauges. Three gauges in a rosette may be used to evaluate the principal strains and the directions of the axes of principal strain and it is this technique which is used to locate the direction of flexural waves travelling along the interface between sea ice and water. The waves are generated by an open-water sea swell impinging on the sea-ice boundary (Wadhams, 1973; Squire and Allan, 1977). The method of rosette analysis though well-established in strain engineering is rarely applied to measure the effects of a propagating wave, and it was felt that a simple theoretical model of the system might yield 
some unexpected results. Using an elastic sheet on a fluid foundation, a dispersion equation is derived which permits a propagating wave. It is this wave which is used to investigate the feasibility of using a strain rosette to obtain directional information for the wave.

The data used in the experimental section were obtained using strainmeters originally developed at the Department of Geophysics, University of Cambridge, for the measurement of earth tides. The instruments were modified for use on ice (Goodman and others, 1975) to a strainmeter of $2 \mathrm{~m}$ gauge length with decreased sensitivity. The experiments were carried out in Notre Dame Bay, Newfoundland as part of a joint venture between the Scott Polar Research Institute and C-CORE, Memorial University of Newfoundland.

\section{DisPersion EQUATION}

To a first approximation the flexural oscillations of sea ice due to ocean swell may be modelled by a thin elastic sheet resting on a fluid foundation of infinite depth (Hendrickson and Webb, 1963$)$.

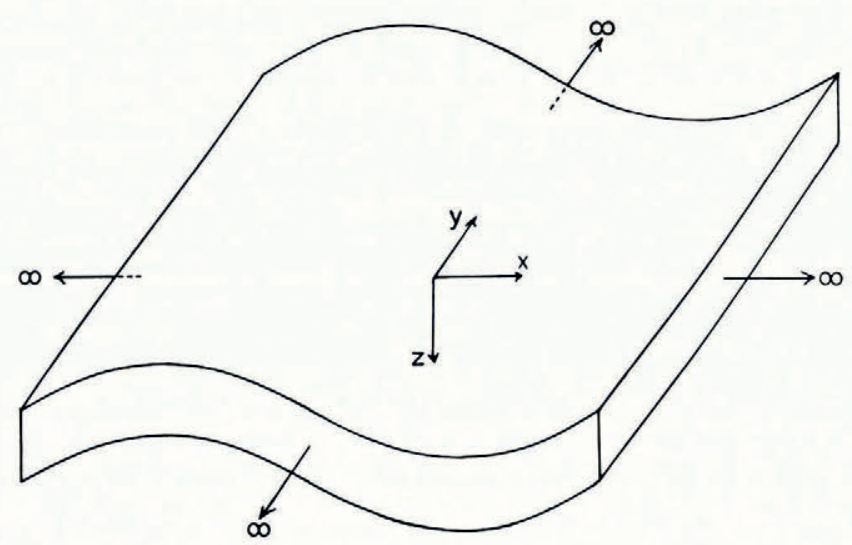

Fig. I. Schematic diagram of wave in ice showing coordinate system.

With the coordinate system shown in Figure $\mathrm{I}$, the equation of the plate is (Hetényi, 1946)

$$
D \nabla^{4} W+\rho_{\mathbf{i}} h \frac{\partial^{2} W}{\partial t^{2}}=P(x, y, t),
$$

where $W(x, y, t)$ is the vertical displacement of the plate, $P(x, y, t)$ is the pressure exerted on the plate by the fluid, $D=h^{3} E / \mathrm{r} 2\left(\mathrm{I}-\nu^{2}\right)$ is the flexural rigidity of the plate, $\nu$ is Poisson's ratio, $E$ is Young's modulus, $\rho_{\mathrm{i}}$ is the density of the plate, and $h$ is the plate thickness. Values of $E=6.0 \times 10^{9} \mathrm{~N} \mathrm{~m}^{-2}, \nu=0.3, \rho_{\mathrm{i}}=922.5 \mathrm{~kg} \mathrm{~m}^{-3}$ were chosen as appropriate values for sea ice.

Within the fluid we may define a velocity potential such that at every point Laplace's equation is satisfied (Stoker, 1957).

$$
\nabla^{2} \phi=0 .
$$

At the ice/water interface we have two boundary conditions, the kinematical condition

$$
\frac{\partial W}{\partial t}=-\left.\frac{\partial \phi}{\partial z}\right|_{z=0}
$$


and Bernoulli's equation

where $\rho$ is the density of the fluid.

$$
P(x, y, t)=-\rho\left[\left.\frac{\partial \phi}{\partial t}\right|_{z=0}+g W(x, y, t)\right],
$$

Hence the equation of motion is

$$
D \nabla^{4} W+\rho_{\mathrm{I}} h \frac{\partial^{2} W}{\partial t^{2}}=-\rho\left[\left.\frac{\partial \phi}{\partial t}\right|_{z=0}+g W\right] .
$$

Consider a plane-wave solution on $z=0$ (Fig. 2)

$$
W=\operatorname{exp~i}\{k(\mathbf{n} \cdot \mathbf{r})-\omega t\},
$$

where $k$ is the wave number, $\mathbf{n}=(l, m)=(\cos \alpha, \sin \alpha)$ is the direction of propagation of the plane wave, $\mathbf{r}$ is the position of an arbitrary point on the plane wave front, and $\omega$ is the circular frequency.

Substitution into the equation of motion gives the required dispersion equation, a quintic polynomial in $k$.

$$
D k^{5}+\left(\rho g-\rho_{1} h \omega^{2}\right) k-\rho \omega^{2}=0 .
$$

We assume that the origin of coordinates is far from the ice edge so that any evanescent waves generated close to the edge (Squire and Allan, 1977) will have died away. $k$ may therefore be regarded as real and positive.

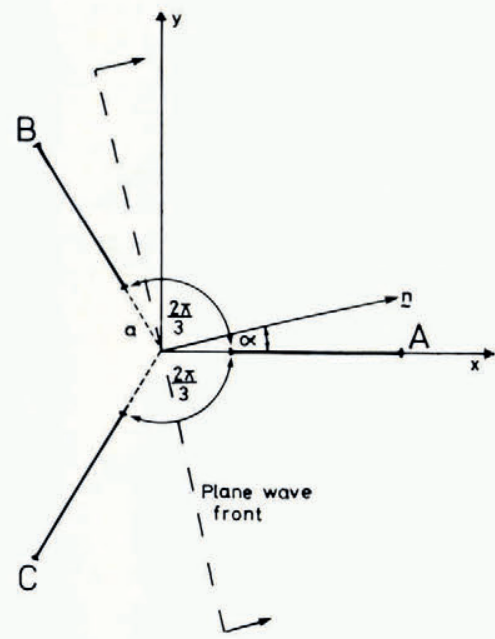

Fig. 2. Plane wave front impinging on a delta rosette $A B C$ with separation parameter a.

\section{Principal aXes}

Now the infinitesimal strain on the surface of the sea ice is given by

(Graff, I975), so that

$$
\epsilon_{x x}=-\frac{h}{2} \frac{\partial^{2} W}{\partial x^{2}}, \quad \epsilon_{x y}=-\frac{h}{2} \frac{\partial^{2} W}{\partial x \partial y}, \quad \epsilon_{y y}=-\frac{h}{2} \frac{\partial^{2} W}{\partial y^{2}},
$$

$$
\left.\begin{array}{l}
\epsilon_{x x}=\frac{1}{2} h l^{2} k^{2} W \\
\epsilon_{x y}=\frac{1}{2} h l m k^{2} W \\
\epsilon_{y y}=\frac{1}{2} h m^{2} k^{2} W
\end{array}\right\}
$$

Consider the strain in some arbitrary direction $\beta$ to the $x$-axis,

$$
\epsilon_{\beta}=\epsilon_{x x} \cos ^{2} \beta+2 \epsilon_{x y} \sin \beta \cos \beta+\epsilon_{y y} \sin ^{2} \beta .
$$




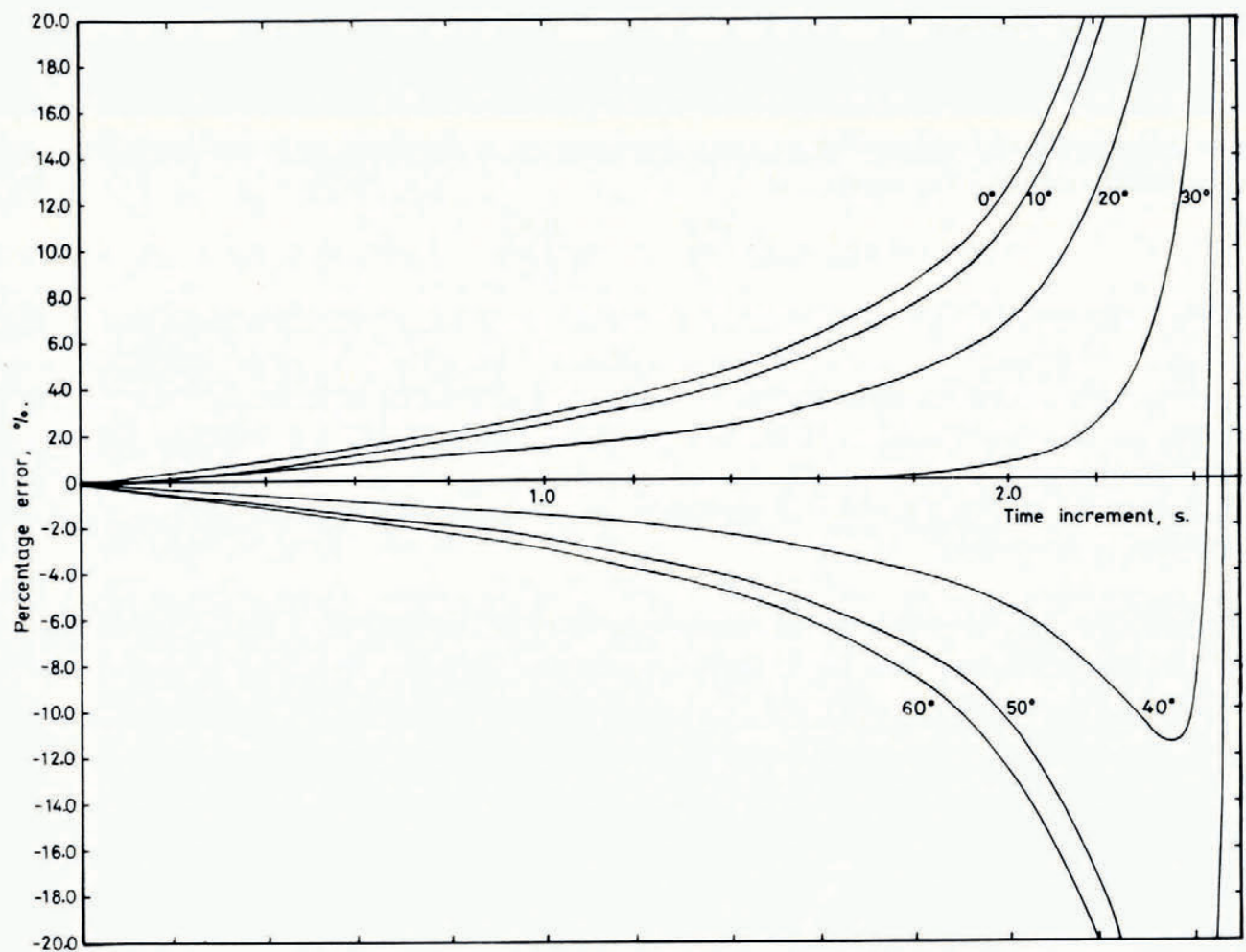

Fig. 3. Percentage error of strain measured by delta rosette as compared with single strainmeter in direction of impinging wave as a function of time increment for various angles of attack. Wave period is $\mathrm{IO}$, separation parameter $a=0.0 \mathrm{~m}$.

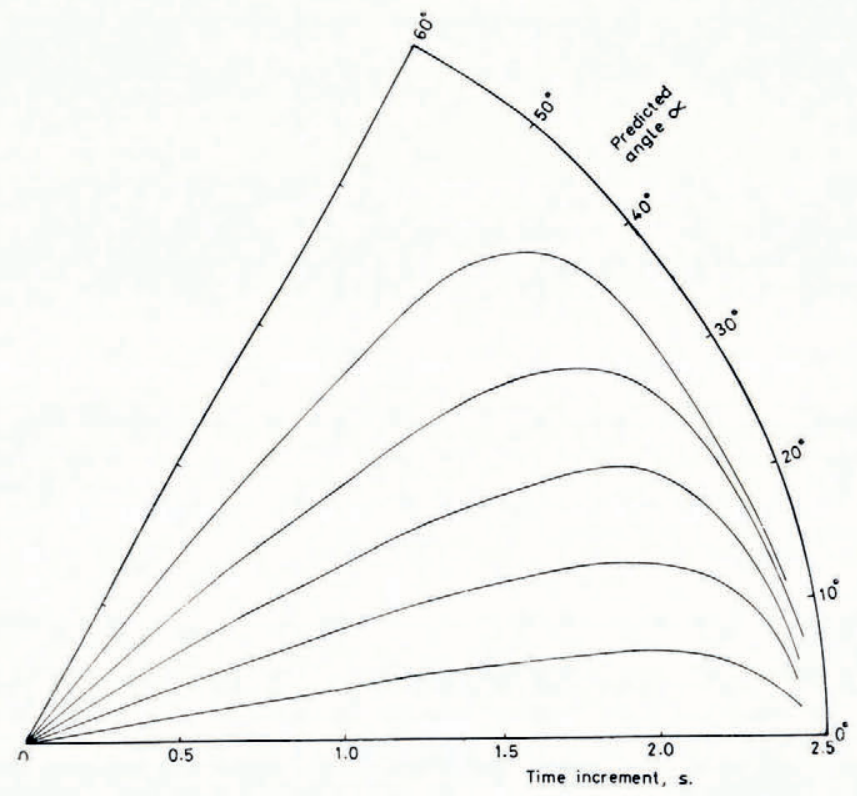

Fig. 4. Predicted angle $\alpha$ as measured by delta rosette as a function of time increment for various angles of attack. Wave period is Io s, separation parameter $a=0.0 \mathrm{~m}$. 
Therefore,

$$
\epsilon_{\beta}=\frac{1}{2} h k^{2} W \cos ^{2}(\alpha-\beta) .
$$

Hence in directions A, B, C (Fig. 2), the respective infinitesimal strains are

$$
\left.\begin{array}{l}
\epsilon_{\mathrm{A}}=\frac{1}{2} h W k^{2} \cos ^{2} \alpha, \\
\epsilon_{\mathrm{B}}=\frac{1}{2} h W k^{2} \cos ^{2}\left(\alpha-\frac{2}{3} \pi\right), \\
\epsilon_{\mathrm{C}}=\frac{1}{2} h W k^{2} \cos ^{2}\left(\alpha+\frac{2}{3} \pi\right) .
\end{array}\right\}
$$

Suppose that the directions A, B, C represent the axes of a $120^{\circ}$ strainmeter rosette. We choose a strainmeter of length $2 \mathrm{~m}$, which corresponds to the instruments used in the experiments and allow a separation from the origin of $a$ (Fig. 2).

Given three strains on a delta rosette ( $120^{\circ}$ rosette, as discussed above) we may locate the axes of principal strain and compute the principal strains $\epsilon_{1}$ and $\epsilon_{2}$ as follows

$$
\left.\begin{array}{l}
\epsilon_{\mathrm{A}}=\frac{1}{2}\left(\epsilon_{\mathrm{I}}+\epsilon_{2}\right)+\frac{1}{2}\left(\epsilon_{\mathrm{I}}-\epsilon_{2}\right) \cos 2 \gamma, \\
\epsilon_{\mathrm{B}}=\frac{1}{2}\left(\epsilon_{\mathrm{I}}+\epsilon_{2}\right)+\frac{1}{2}\left(\epsilon_{\mathrm{I}}-\epsilon_{2}\right) \cos 2\left(\gamma+\frac{2}{3} \pi\right), \\
\epsilon_{\mathrm{C}}=\frac{1}{2}\left(\epsilon_{\mathrm{I}}+\epsilon_{2}\right)+\frac{1}{2}\left(\epsilon_{\mathrm{I}}-\epsilon_{2}\right) \cos 2\left(\gamma+\frac{4}{3} \pi\right),
\end{array}\right\}
$$

where $\gamma$ is the angle between the axes of principal strain and one strainmeter of the strain rosette. After some algebra these equations lead to

$$
\begin{aligned}
\epsilon_{1}+\epsilon_{2} & =\frac{2}{3}\left(\epsilon_{\mathrm{A}}+\epsilon_{\mathrm{B}}+\epsilon_{\mathrm{C}}\right), \\
\epsilon_{\mathrm{I}}-\epsilon_{2} & = \pm \frac{4}{3}\left(\epsilon_{\mathrm{A}}^{2}+\epsilon_{\mathrm{B}}{ }^{2}+\epsilon_{\mathrm{C}}{ }^{2}-\epsilon_{\mathrm{A}} \epsilon_{\mathrm{B}}-\epsilon_{\mathrm{B}} \epsilon_{\mathrm{C}}-\epsilon_{\mathrm{C}} \epsilon_{\mathrm{A}}\right)^{\frac{1}{2}}, \\
\tan 2 \gamma & =\frac{3^{\frac{1}{2}}\left(\epsilon_{\mathrm{B}}-\epsilon_{\mathrm{C}}\right)}{2 \epsilon_{\mathrm{A}}-\epsilon_{\mathrm{B}}-\epsilon_{\mathrm{C}}} .
\end{aligned}
$$

The cundition $\left|\epsilon_{1}\right| \geqslant\left|\epsilon_{2}\right|$ fixes the sign of $\epsilon_{1}-\epsilon_{2}$ and any ambiguity in the angle $\gamma$.

Given an incident wave of particular period and angle of attack $\alpha$, it is therefore possible to compare the expected surface strain and angle $\alpha$ with that calculated from the delta rosette. The percentage error in surface strain as a function of incremental time for a $10 \mathrm{~s}$ wave at angles of attack of $0^{\circ}$ through $60^{\circ}$ in steps of $10^{\circ}$ is shown in Figure 3. The predicted angle $\alpha$ is shown for various angles of attack in Figure 4.

As the wave propagates past the strain rosette, each instrument will sample a different part of its cycle due to their physical separation. This will introduce a frequency-dependent phase difference between the strainmeters leading to the large errors (particularly where the strain goes through zero) shown in Figures 3 and 4. A choice of $a=-1.0 \mathrm{~m}$ (half the physical length of the instrument) will eliminate the error completely, but it is not feasible experimentally to position the instrument in a star configuration with sufficient accuracy.

A monochromatic wave of known direction is not a realistic forcing and one might encounter a sea made up of waves and swell of many periods from several directions. The errors then become so unpredictable that continuous computation in the time domain is not a viable method for evaluating the direction of wave propagation and the associated principal strains.

\section{FREQUENCY-DOMAIN ANALYSIS}

An alternative to time-series analysis is to compute a power spectral density for each strainmeter in the rosette every five minutes over several hours. From the power spectral density a root-mean-square strain about some centre frequency may be found by integration over a small frequency band-width and then taking the square root. A band-width of 5/320 $\mathrm{Hz}$ was used throughout. In this way the strain corresponding to discrete peaks in the power spectral density may be treated independently. 
The power spectral densities were evaluated for data obtained over several hours on fast ice in Notre Dame Bay, Newfoundland, using a Hewlett-Packard 545 $\mathrm{IB}$ Fourier Analyser system located at Memorial University of Newfoundland (Allan and Squire, 1977). There were clear peaks at approximately $6 \mathrm{~s}$ and $\mathrm{i} 3 \mathrm{~s}$ and it was the strains corresponding to these peaks which were used in the principal strain calculation. Figures 5 and 6 show the variation of the orientation of the axes of principal strain and the principal strains as a function of elapsed time for the recorded io $h$ of data.

The mean and standard deviation of the orientation angle weighted with respect to the larger principal strain was found for both the long- and short-period components. For II2 samples the means of the two components were $2.4^{\circ}$ and $-13.6^{\circ}$ respectively and the standard deviations, $7.8^{\circ}$ and $7 \cdot 3^{\circ}$. A Student's $t$-test gave independent distributions with $99 \cdot 9 \%$ confidence indicating that the waves were propagating from different directions and had

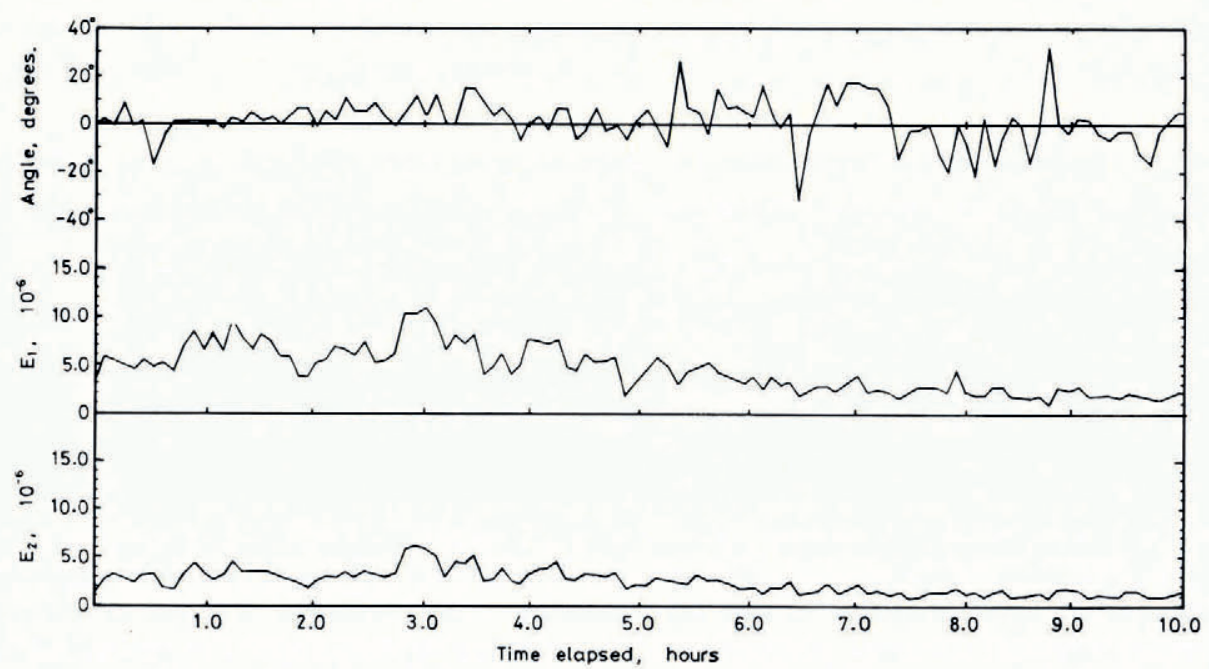

Fig. 5. Variation of orientation of principal axes of strain and principal strains for long-period component over $10 h$.

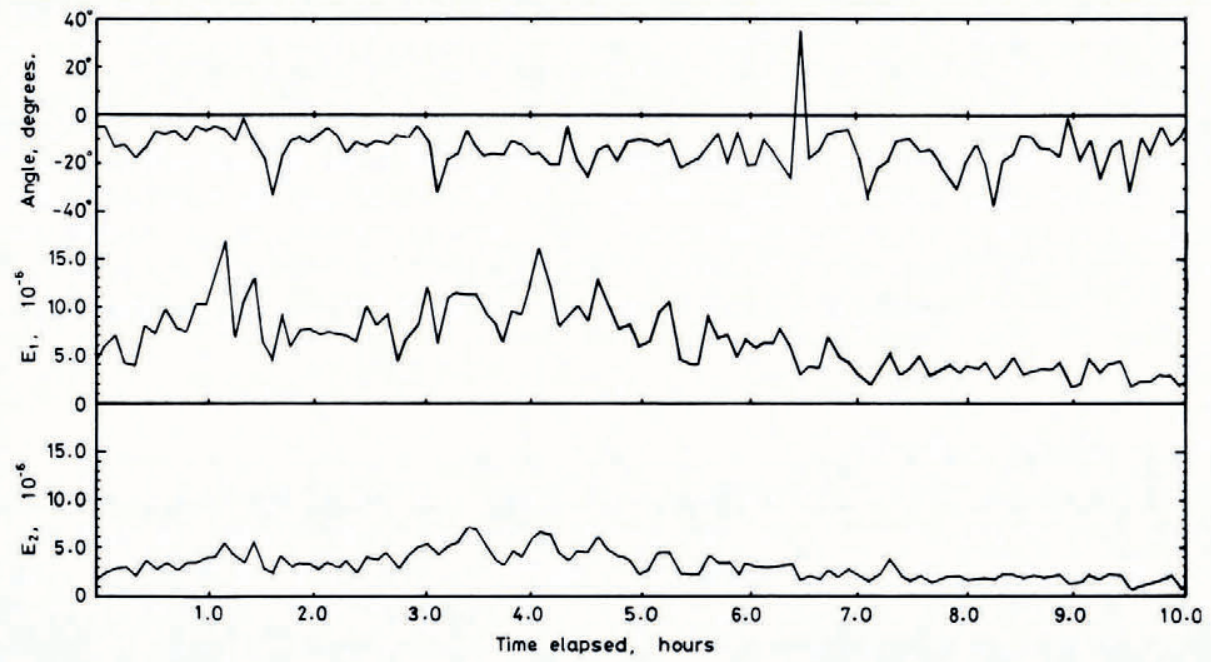

Fig. 6. Variation of orientation of principal axes of strain and principal strains for short-period component over $10 h$. 
originated from different sources. The predicted directions were the same as those observed visually over the duration of the experiment.

The orientation of the axes of principal strain with time depends upon the interference of the individual components of the wave spectrum. A predominant swell normal to the ice edge will generate a flexural wave travelling in the same direction. Waves impinging from other directions will interfere with the basic wave to produce a swing in the principal axes. This mechanism is a possible explanation for the parallel cracks which often form at an angle to the apparent incident swell during the wave break-up of sea ice. It also hints that a relationship between crack spacing and incident wavelength may not be as simple as was first imagined.

\section{Discussion}

In addition to the inaccuracies introduced by the physical length of a strain gauge we have found considerable errors due to the separation of the instruments in a strain rosette. Theoretically such errors may be removed by superposition of the instruments to form a star configuration but this is not feasible experimentally. Since most strain rosettes used at present in both mechanical and ice engineering do have their gauges separated by some small but finite distance it is very important to take this into account when measuring propagating strain waves.

In geophysical applications, such as that described here, the random nature of the forcing makes it impossible to eliminate errors if the principal-axes approach is used. We have thus shown that it is essential to employ frequency-domain analysis for the treatment of data obtained by strainmeter rosettes.

\section{Acknowledgements}

This work was carried out while the author was in receipt of a research studentship from the Natural Environment Research Council of Great Britain. I am indebted to Dr Peter Wadhams and Alastair Allan for invaluable discussion. I also thank members of C-CORE and in particular the Twillingate field party whose cheerfulness and stimulating conversation led to a successful experiment.

MS. received 28 October 1977

\section{REFERENCES}

Allan, A. J., and Squire, V. A. In press. Naturally induced surface strain in fast ice. C-CORE Publication (Memorial University of Newfoundland. Centre for Cold Ocean Resources Engineering).

Dally, J. W., and Riley, W. F. I965. Experimental stress analysis. New York, McGraw-Hill Book Co., Inc.

Dove, R. C., and Adams, P. H. 1964 . Experimental stress analysis and motion measurement. (Theory, instruments and circuits, techniques.) Columbus, Ohio, Charles E. Merrill Publishing Co.

Goodman, D. J., and others. 1975. Wire strainmeters on ice, [by] D. J. Goodman, A. J. Allan, R. G. Bilham. Nature, Vol. 255, No. 5503, p. 45-46.

Graff, K. F. I975. Wave motion in elastic solids. Oxford, Clarendon Press. (Oxford Engineering Science Series.)

Hendrickson, J. A., and Webb, L. M. I963. Theoretical investigation of semi-infinite ice floes in water of infinite depth. Port Hueneme, California, U.S. Naval Civil Engineering Laboratory. (NBy-32225, Final Report.)

Hetényi, M. I. 1946. Beams on elastic foundations; theory with applications in the fields of civil and mechanical engineering. Ann Arbor, University of Michigan Press. (University of Michigan Studies. Scientific Series, Vol. I6.)

Murphy, G., and others. I957. Response of resistance strain gages to dynamic strains, by G. Murphy, A. H. Hausrath III and P. W. Peterson. IXe Congrès International de Mécanique Appliquée. Actes. [1956.] Tom. 8,
p. $44^{8-56 .}$

Squire, V. A., and Allan, A. J. 1977. Propagation of flexural gravity waves in sea ice. A symposium on sea ice processes and models, [Seattle, U.S.A.,] September 6-9, 1977. Preprints, Vol. 2, p. $157-66$.

Stoker, J. J. 1957. Water waves. The mathematical theory with applications. New York, Interscience.

Wadhams, P. 1973. Attenuation of swell by sea ice. Journal of Geophysical Research, Vol. 78, No. 18, p. 3552-63. 